\title{
ENTRAINMENT AND MIXING OF TRANSPORTED OZONE LAYERS: IMPLICATIONS FOR SURFACE AIR QUALITY IN THE WESTERN U.S.
}

\author{
Christoph Senff ${ }^{*}$, Andrew Langford2, Raul Alvarez II2, Tim Bonin1, Alan Brewer2, Aditya \\ Choukulkar1, Guillaume Kirgisı, Richard Marchbanks1, Scott Sandberg2, Ann Weickmann1, \\ Michael Zucker 1 \\ IUniversity of Colorado CIRES at NOAA ESRL Chemical Sciences Division, Boulder, CO, USA \\ 2NOAA ESRL Chemical Sciences Division, Boulder, CO, USA \\ *Email: christoph.senff@noaa.gov
}

\begin{abstract}
Recently, two air quality campaigns were conducted in the southwestern United States to study the impact of transported ozone, stratospheric intrusions, and fire emissions on ground-level ozone concentrations. The California Baseline Ozone Transport Study (CABOTS) took place in May - August 2016 covering the central California coast and San Joaquin Valley, and the Fires, Asian, and Stratospheric Transport Las Vegas Ozone Study (FAST-LVOS) was conducted in the greater Las Vegas, Nevada area in May June 2017. During these studies, nearly 1000 hours of ozone and aerosol profile data were collected with the NOAA TOPAZ lidar. A Doppler wind lidar and a radar wind profiler provided continuous observations of atmospheric turbulence, horizontal winds, and mixed layer height. These measurements allowed us to directly observe the degree to which ozone transport layers aloft were entrained into the boundary layer and to quantify the resulting impact on surface ozone levels. Mixed layer heights in the San Joaquin Valley during CABOTS were generally below $1 \mathrm{~km}$ above ground level (AGL), while boundary layer heights in Las Vegas during FAST-LVOS routinely exceeded $3 \mathrm{~km}$ AGL and occasionally reached up to $4.5 \mathrm{~km}$ AGL. Consequently, boundary layer entrainment was more often observed during FAST-LVOS, while most elevated ozone layers passed untapped over the San Joaquin Valley during CABOTS.
\end{abstract}

\section{INTRODUCTION}

Ground-level ozone $\left(\mathrm{O}_{3}\right)$ concentrations in the U.S. are often driven by local production, especially in and near urban areas. However, stratosphere-to- troposphere transport (STT) and long-range transport from Asia can also have significant impacts on surface $\mathrm{O}_{3}$ levels, particularly in the western U.S. Ozone-rich air from the lower stratosphere can be carried into the lower free troposphere by stratospheric intrusions that are spawned by upper-level cyclones. This phenomenon peaks in late spring when cyclonic activity remains high and the $\mathrm{O}_{3}$ content of the lower stratosphere is at a maximum. Also, many of these intrusions entrain pollution plumes transported across the Pacific Ocean from Asia as they descend through the troposphere and bring this ozone-enriched air toward the surface with them. Global model simulations $[1,2]$ indicate that STT and Asian pollution contributions to U.S. surface $\mathrm{O}_{3}$ in late spring are largest in the Southwest and the Intermountain West. The higher terrain there and deeper boundary layers compared to the rest of the country increase the likelihood that descending ozone-rich air reaches the surface [3]. $\mathrm{O}_{3}$ produced in wildfire plumes is another potential source of increased surface $\mathrm{O}_{3}$. High $\mathrm{O}_{3}$ associated with STT, Asian pollution, and wildfire plumes is often concentrated in elevated layers in the lower free troposphere that need to be transported to the surface to affect ground-level $\mathrm{O}_{3}$ concentrations. This can be accomplished by entrainment into the well-mixed boundary layer, isentropic transport directly to the surface in very deep intrusions, or terrain-modulated flow patterns.

To study the relative impact of these three sources on surface air quality compared to local $\mathrm{O}_{3}$ production and to characterize the processes that transport the elevated $\mathrm{O}_{3}$ layers to the surface, the CABOTS and FAST-LVOS air quality campaigns were conducted in May-August 2016 along the central California coast and the San Joaquin Valley 


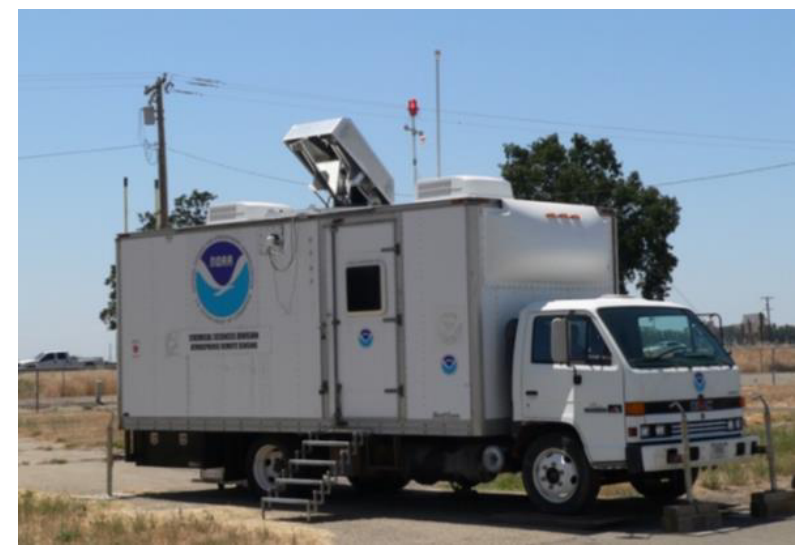

Figure 1: TOPAZ lidar truck at Visalia Municipal Airport during CABOTS.

(SJV) and in May-June 2017 in the Las Vegas Valley (LVV), respectively. Both, the SJV and the LVV often exceed the 8-hour $\mathrm{O}_{3}$ National Ambient Air Quality Standard (NAAQS). However, the SJV suffers from more severe $\mathrm{O}_{3}$ exceedances and has been designated as one of only two "extreme" nonattainment areas in the U.S.

\section{METHODOLOGY}

The NOAA ESRL Chemical Sciences Division (CSD) truck-based Tunable Optical Profiler for Aerosols and oZone (TOPAZ) lidar [4,5] (Figure 1) was a key component of both studies and was deployed at the Visalia Municipal Airport (VMA)

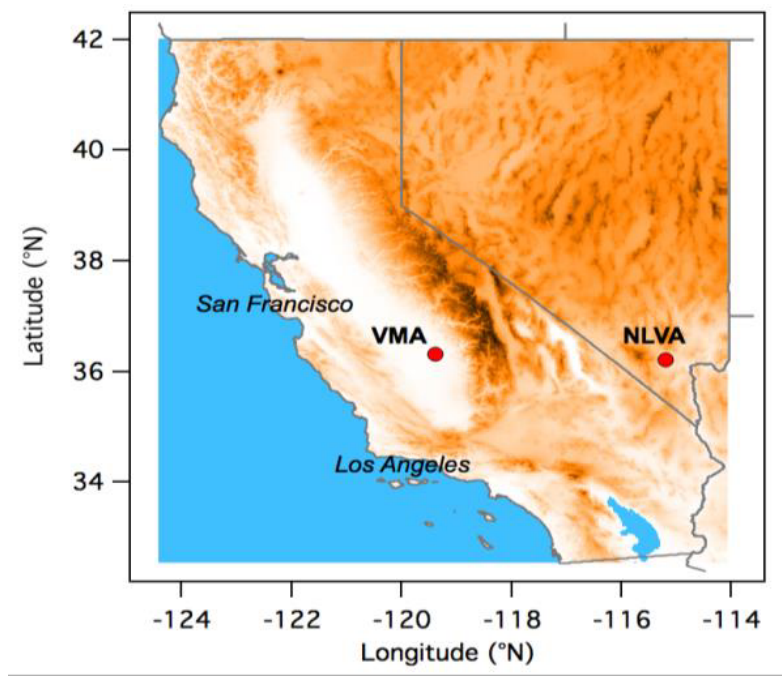

Figure 2: Locations of the NOAA lidars at Visalia, $C A$ (VMA) during CABOTS and at Las Vegas, NV (NLVA) during FAST-LVOS. during CABOTS and the North Las Vegas Airport (NLVA) during FAST-LVOS (Figure 2). TOPAZ uses the Differential Absorption Lidar (DIAL) technique to measure ozone as a function of distance from the lidar. A large scanning mirror on top of the TOPAZ truck permits scanning of the laser beam at a series of different elevation angles to measure ozone from $25 \mathrm{~m}$ to nearly $6 \mathrm{~km}$ above the surface during the day, and $8 \mathrm{~km}$ at night. TOPAZ is part of the NASA-sponsored Tropospheric Ozone Lidar Network (TOLNet). The autonomous, zenith-looking NOAA/ESRL/CSD MicroDoppler wind lidar was deployed next to TOPAZ during part of CABOTS $(7 / 28-8 / 7 / 2016)$ and for the entire FAST-LVOS study to provide continuous observations of vertical wind speed, turbulence, and mixed layer height. The continuously operating San Joaquin Valley Air Pollution Control District (SJVAPCD) radar Radio Acoustic Sounding System (RASS) system, located at VMA, measures horizontal wind and virtual temperature profiles. The latter were used to compute hourly mixed layer height estimates during CABOTS.

\section{RESULTS}

The TOPAZ observations revealed a complex vertical ozone structure during the CABOTS and FAST-LVOS studies, including distinct highozone layers in the free troposphere associated with stratospheric intrusions, long-range transport from Asia, wildfire plumes, and regional pollution transport. The deployment locations of the NOAA lidars during the two studies (VMA during CABOTS and NLVA during FAST-LVOS, see Figure 2), were roughly at the same latitude and only $\sim 400 \mathrm{~km}$ apart, however, the mixed layer height (MLH) characteristics were dramatically different. Afternoon MLHs were very shallow at Visalia, CA during CABOTS (200 - 1200 m AGL, Figure 3), which is due to strong subsidence associated with synoptic-scale high pressure and the valley-mountain circulation in California's Central Valley. In contrast, MLHs were much deeper and more variable at Las Vegas, NV during FAST-LVOS (1300 - $4500 \mathrm{~m}$ AGL, Figure 3). The different MLH regimes have important ramifications for boundary layer entrainment of 
transported $\mathrm{O}_{3}$ layers and for potential impacts on surface $\mathrm{O}_{3}$ concentrations.

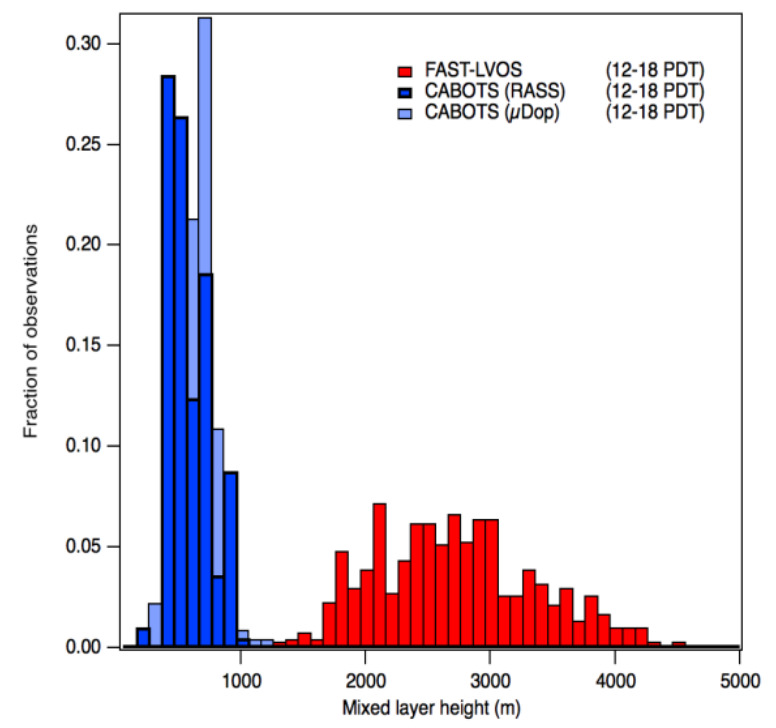

Figure 1: Distribution of observed afternoon mixed layer heights at VMA during CABOTS (from SJVAPCD radar RASS, dark blue; from MicroDoppler lidar, light blue, 7/28-8/7/2016) and during FAST-LVOS (from MicroDoppler lidar, red).

\subsection{CABOTS}

Figure 4 shows the $\mathrm{O}_{3}$ distribution observed with TOPAZ on 20 July 2016 during CABOTS (full $\mathrm{O}_{3}$ profiles up to $8 \mathrm{~km}$ AGL, top panel; $\mathrm{O}_{3}$ profiles in the lowest $2.5 \mathrm{~km}$ AGL with horizontal wind and MLH observations overlaid, bottom panel). On this day, a low-altitude $\mathrm{O}_{3}$ layer was entrained into the boundary layer in the early afternoon, which increased surface $\mathrm{O}_{3}$ by several ppbv. This layer likely was formed by locally produced $\mathrm{O}_{3}$ that had been transported into the Sierra Nevada Foothills by upslope flow the day before and then was recirculated over the SJV in an easterly return flow, as indicated by the radar RASS measured winds in Figure 4 (bottom panel). The high-O3 layer between 4 and $6 \mathrm{~km}$ AGL was of stratospheric and/or Asian origin and passed over the SJV, well out of reach of the shallow mixed layer. Similar observations on several other days during CABOTS confirmed that the mixed layer in the SJV was not nearly deep enough to entrain freetropospheric $\mathrm{O}_{3}$ layers associated with STT and transport from Asia, except for one exceptionally deep stratospheric intrusion event.
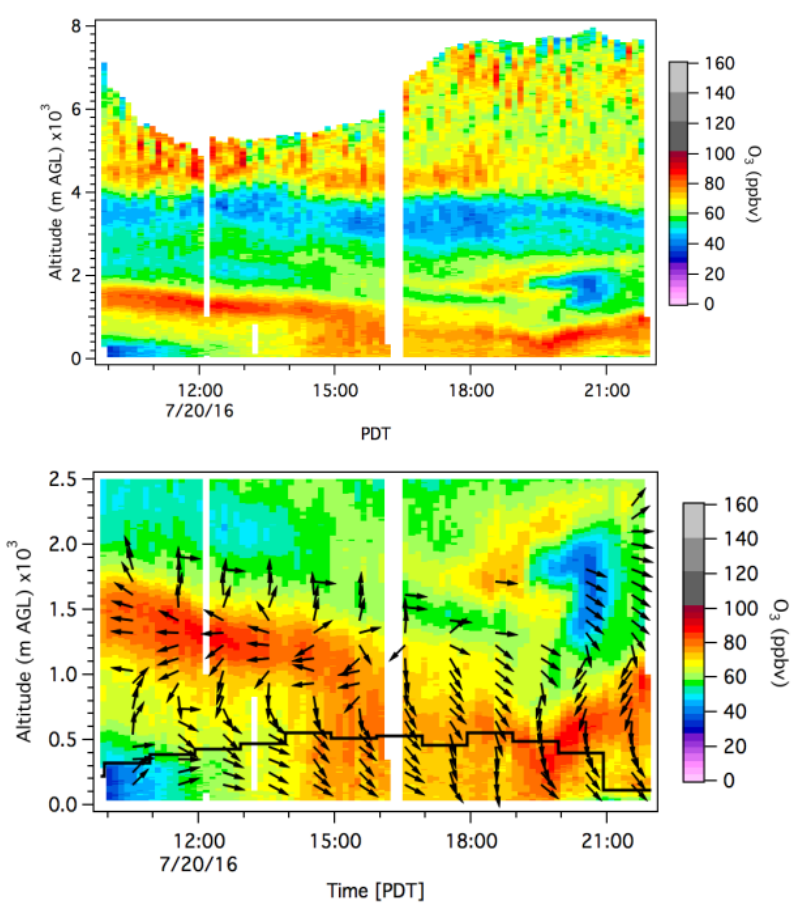

Figure 2: TOPAZ ozone profiles observed on 20 July 2016 during CABOTS. Radar RASS mixed layer heights (black line) and wind arrows are overlaid (bottom panel).

\subsection{FAST-LVOS}

During FAST-LVOS, we often observed partial or complete entrainment of elevated $\mathrm{O}_{3}$ layers of stratospheric or Asian origin into the boundary layer. Figure 5 shows the $\mathrm{O}_{3}$ profiles observed with TOPAZ on 28 June 2017 during the FAST-LVOS campaign. On that day, a narrow $\mathrm{O}_{3}$ layer that likely was of Asian origin and contained $\mathrm{O}_{3}$ concentrations in excess of $100 \mathrm{ppbv}$ descended to $2.5 \mathrm{~km}$ AGL by midday, when it was completely engulfed by the growing mixed layer in the LVV. We estimate that the entrainment of this transported $\mathrm{O}_{3}$ layer resulted in $\mathrm{a} \sim 5 \mathrm{ppbv}$ increase in surface ozone concentrations. This rather small, but still significant $\mathrm{O}_{3}$ enhancement may have contributed to $\mathrm{O}_{3} \mathrm{NAAQS}$ exceedances that were observed by the regulatory monitoring network in the LVV on that day. We observed several similar cases that resulted in estimated surface $\mathrm{O}_{3}$ enhancements of up to $12 \mathrm{ppbv}$. 


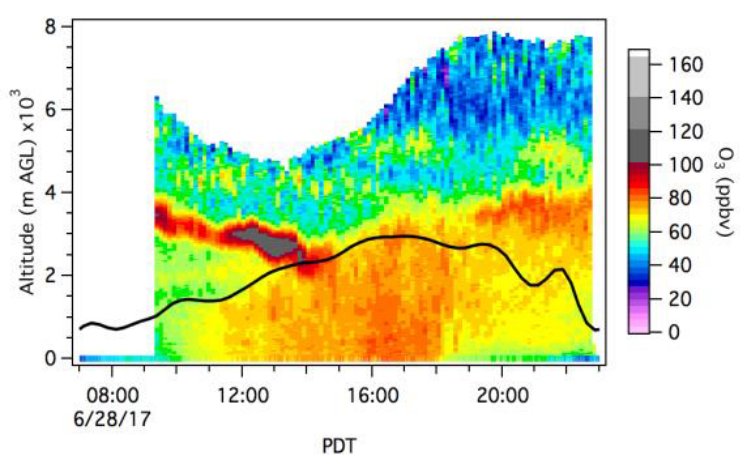

Figure 3: TOPAZ ozone profiles observed on 28 June 2017 during FAST-LVOS. MicroDoppler lidar mixed layer heights (black line) are overlaid.

\section{CONCLUSIONS}

Shallow mixed layers in California's San Joaquin Valley strongly limited entrainment of transported $\mathrm{O}_{3}$ layers associated with stratospheric intrusions, Asian transport, and wildfire plumes. Most of these elevated $\mathrm{O}_{3}$ layers passed over the San Joaquin Valley untapped. In contrast, deep mixed layers in the Las Vegas Valley frequently entrained transported $\mathrm{O}_{3}$ layers from altitudes as high as $5 \mathrm{~km}$ above sea level. As a result, surface $\mathrm{O}_{3}$ levels often increased, which likely contributed to exceedances of the $\mathrm{O}_{3} \mathrm{NAAQS}$ in the Las Vegas area.

\section{ACKNOWLEDGEMENTS}

This work was funded in part by the California Air Resources Board (CARB) under contract no. 15RD012, by the Clark County Department of Air Quality under contract no. CBE 604318-16, and by the NASA-sponsored Tropospheric Ozone Lidar Network (TOLNet).

\section{REFERENCES}

[1] Lin, M. Y., et al. (2012a), Springtime high surface ozone events over the western United States: Quantifying the role of stratospheric intrusions, J. Geophys. Res., 117, D00v22, doi:10.1029/2012jd018151.

[2] Lin, M. Y., et al. (2012b), Transport of Asian ozone pollution into surface air over the western United States in spring, J. Geophys. Res., 117,
D00v07, doi:10.1029/2011JD016961.

[3] Langford, A. O., et al. (2017), Entrainment of stratospheric air and Asian pollution by the convective boundary layer in the southwestern U.S, J. Geophys. Res., 122(2), 1312-1337, doi:10.1002/2016JD025987.

[4] Alvarez, R. J., et al, 2011: Development and application of a compact, tunable, solid-state airborne ozone lidar system for boundary layer profiling, J. Atmos. Ocean. Technol, doi: 10.1175/JTECH-D-10-05044.1

[5] Alvarez, R. J., Senff, C. J., A. M. Weickmann, S. P. Sandberg, A. O. Langford, R. D. Marchbanks, W. A. Brewer, and R. M. Hardesty, 2012: Reconfiguration of the NOAA TOPAZ Lidar for Ground-based Measurement of Ozone and Aerosol Backscatter, Proceedings of the 26th International Laser Radar Conference, Porto Heli, Greece, 25-29 June 2012, pp. 249-252. 